\title{
Design, synthesis and pharmacological evaluation of 4-[2-alkylthio-5(4)-(4- substitutedphenyl)imidazole-4(5)yl]benzenesulfonamides as selective COX-2 inhibitors ${ }^{1}$
}

\author{
Mona SALIMI ${ }^{2}$, Mohammad Hossein GHAHREMANI ${ }^{3}$, Nima NADERI $^{4}$, Mohsen AMINI ${ }^{5}$, Elika SALIMI ${ }^{6}$, Massoud \\ AMANLOU $^{5}$, Khosrou ABDI $^{5}$, Raha SALEHI ${ }^{3}$, Abbas SHAFIEE $^{5,7}$ \\ ${ }^{2}$ Research and Development Center, Pasteur Institute of Iran, Kasas, Iran; ${ }^{3}$ Department of Pharmacology and Toxicology, Faculty of Pharmacy and \\ Pharmaceutical Sciences Research Center, Tehran University of Medical Sciences, Tehran, Iran; ${ }^{4}$ Neuroscience Research Center, Shahid Beheshti \\ University of Medical Sciences, Tehran, Iran; ${ }^{5}$ Department of Medicinal Chemistry, Faculty of Pharmacy and Pharmaceutical Sciences Research \\ Center, Tehran University of Medical Sciences, Tehran, Iran; ${ }^{6}$ Department of Pharmacology, Faculty of Pharmacy, Mazanderan University of Medical \\ Sciences, Sari, Iran
}

\section{Key words}

cyclooxygenase-2 inhibitor; imidazole; alkylthio; celecoxib

\author{
${ }^{1}$ This project was supported by grants from \\ the research council of Tehran University \\ of Medical Sciences and Iran Chapter of \\ TWAS (The Developing World of Academy \\ of Sciences), and INSF (Iran National Science \\ Foundation). \\ ${ }^{7}$ Correspondence to Dr Abbas SHAFIEE. \\ Phn 98-2 1-6640-6757. \\ Fax 98-21-6646-1178. \\ E-mail ashafiee@ams.ac.ir \\ Received 2006-10-23 \\ Accepted 2007-01-07
}

doi: $10.1111 /$ j.1745-7254.2007.00619.x

\begin{abstract}
Aim: To design and synthesize a series of benzenesulfonamide derivatives, 4-[2alkylthio-5(4)-(4-substitutedphenyl)imidazole-4(5)-yl]benzenesulfonamides (4a-4j), which are intended to act as cyclooxygenase-2 (COX-2) inhibitors with good COX-2 inhibitor activity, and which will exert anti-inflammatory activities in vivo. Methods: Benzenesulfonamide derivatives were designed and synthesized through multi-step chemical reactions. All the synthesized compounds were evaluated in an in vitro assay. The active compound $4 \mathrm{a}-4 \mathrm{f}$ was selected for further evaluation in a carrageenan-induced rat paw edema model. Results: Docking studies showed that compound 4 bind into the primary binding site of COX-2 with the sulfonamide $\mathrm{SO}_{2} \mathrm{NH}_{2}$ moiety interacting with the secondary pocket amino acid residues. In the in vitro assay, compound 4 inhibited $\mathrm{COX}-2$ with an inhibition concentration $\mathrm{IC}_{50}$ value of $1.23-8 \mathrm{nmol} / \mathrm{L}$, compared to celecoxib with $\mathrm{IC}_{50}$ value of $1.5 \mathrm{nmol} / \mathrm{L}$. Compound $4 \mathrm{~b}$ and $4 \mathrm{c}$ had good potency and selectivity in comparison to the celecoxib. In the in vivo model, compound $4 \mathrm{a}-4 \mathrm{f}$ exhibited a moderate potency to inhibit $50 \%$ carrageenan-induced paw edema with value of $1.58-4.3 \mathrm{mg} / \mathrm{kg}$. In the latter experiment, compound $4 \mathrm{c}$ was the most active compound. Conclusion: The antiinflammatory effects obtained for compound $4 \mathrm{a}-4 \mathrm{j}$ could be due to the presence of fluorine or hydrogen substituents in the para position of the phenyl ring of these compounds.
\end{abstract}

\section{Introduction}

Non-steroidal anti-inflammatory drugs (NSAID) are among the most widely used prescriptions, primarily for the treatment of pain, bronchial asthma, allergy, and inflammation $^{[1]}$. Although modifications of established non-selective agents, such as the lengthening of the carboxyl side chain of indomethacin ${ }^{[2]}$ have been strategies for the design of cyclooxygenase-2 (COX-2) selective inhibitor ${ }^{[3]}$, the main effort has been addressed to the diarylheterocycle class ${ }^{[4]}$. Many lead compounds reported to have selective COX-2 inhibitory activity have been clinically introduced to reduce inflammation with very little gastrointestinal GI side effects, namely, celecoxib ${ }^{[5]}$, rofecoxib $^{[6]}$, valdecoxib ${ }^{[7]}$, lumiracoxib, etoricoxib ${ }^{[8]}$, and nimesulide. Also, recent studies have shown that selective COX-2 inhibitors can induce apoptosis in the colon, stomach, prostate, and breast cancer cell lines $^{[9-13]}$.

Overall, these selective COX-2 inhibitors have fulfilled the hope of exhibiting a reduced risk in gastrointestinal events ${ }^{[14]}$; however, the increased incidence of non-gastrointestinal, serious, adverse events with the COX-2 selective 


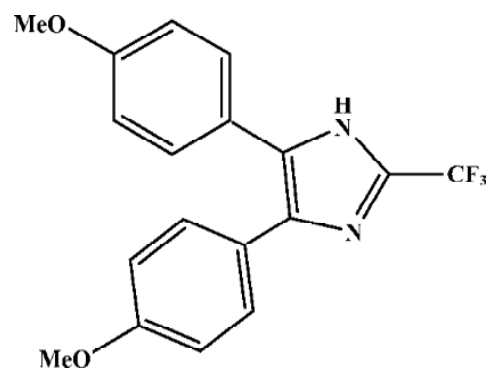

Figure 1. Structure of flunizole.

inhibitors as compared with non-selective NSAID in the Celecoxib Long-term Arthritis Safety Study and the Vioxx Gastrointestinal Outcomes Research study, remains a major concern $^{[15]}$. With all these aspects considered, developing drugs that preferentially inhibit COX-2 with moderate potency and selectivity was of interest, since the currently used, very selective COX-2 inhibitors cause unwanted side effects in a significant amount of people ${ }^{[16]}$.

Flumizole, an early known 4,5-diarylimidazole (Figure 1), and 4,5-diaryl-2-substituted thioimidazole, have been reported to exhibit anti-inflammatory activity ${ }^{[14,17]}$. As a part of our ongoing research to design novel selective COX-2 inhibitors $^{[18-23]}$, we describe herein, the design and biological evaluation of 4-[2-alkylthio-5(4)-(4-substitutedphenyl)imidazole-4(5)-yl]benzenesulfonamides as COX-2 inhibitors with anti-inflammatory activities.

\section{Materials and methods}

Animals Male Sprague Dawley rats, weighing 150-200 g $(n=6)$, were supplied by Razi Institute, Tehran, Iran. All the animals were housed in Plexiglas cages on a 12/12 h light/ dark cycle in temperature- and humidity-controlled rooms. Food was withheld $24 \mathrm{~h}$ before the experiments, but with free access to water. All the experiments confirmed to the guidelines of the committee on animal experiments at Tehran University of Medical Sciences (Tehran, Iran)

Chemicals and reagents All of the chemicals and reagents were purchased from Merck (KGaA, Darmstadt, Germany) and Sigma-Aldrich (St Louis, MO, USA).

Molecular modeling and chemistry Docking studies were performed using the Autodock 3.05 Package (Scripps Research Institute, La Jolla, California $)^{[24-26]}$. The coordinates of the X-ray crystal structure of selective COX-2 inhibitor S-58701 (B) bound to the murine COX-2 enzyme was obtained from the Protein Data Bank (www.rcsb.org) code $1 \mathrm{CX} 2$ and hydrogens were added. The ligand molecules were constructed using Chem-3D (CambridgeSoft,
Cambridge, MA) and were minimized for 500 iterations, reaching a convergence of $0.01 \mathrm{kcal} / \mathrm{mol} \AA$. The compound 4 was docked using Lamarckian genetic algorithm (LGA), where the number of $\mathrm{GA}=10$, the population size $=50$, and the maximum number of energy evaluations is 250000 . The result was analyzed using root mean square deviation (RMSD), estimated inhibition constant $\left(K_{\mathrm{i}}\right)$, and estimated free energy of binding $(\Delta G)$. The best resulting $\Delta G=-11.5 \mathrm{kcal} / \mathrm{mol}$ was for compound $4 \mathrm{c}$ with RMSD $2.115 \AA$. The $K_{\mathrm{i}}$ was $3.72 \times 10^{-9}$.

The 4,5-diarylimidazole-2-thiones (compound 2), with substituents at the para position of one of the phenyl rings, was prepared in high yield (80\%-90\%) using ammonium thiocyanate and 2-oxo-1,2-diphenylethyl benzoates (compound 1) in amyl alcohol at $150-160^{\circ} \mathrm{C}$. Subsequent alkylation of compound 2 with alkyl iodide in methanol in the presence of triethylamine afforded 2-alkylthio-4,5-diarylimidazoles (compound 3, 24\%-81\%). The sequential chlorosulfonation of compound 3 with chlorosulfonic acid, followed by ammonia gave 4-[2-alkylthio-5(4)-(4-substitutedphenyl)imidazole4(5)yl]benzenesulfonamides (compound 4). The structure of compound 4 was confirmed by infrared, by proton nuclear magnetic resonance and Mass spectrometry ${ }^{[23]}$.

\section{Biological assays}

In vitro COX inhibition assay COX activity was determined by using arachidonic acid (AA) as substrate and $N, N$, $\mathrm{N}, \mathrm{N}$-tetramethylphenylenediamine (TMPD) as the cosubstrate, as previously described ${ }^{[18,19,27]}$. The reaction mixture $(200 \mu \mathrm{L})$ contained $0.5 \mu \mathrm{mol} / \mathrm{L}$ heme, $0.05 \mathrm{mmol} / \mathrm{L}$ TMPD, $0.1 \mathrm{mmol} / \mathrm{LAA}$, and 36 units of the COX-2 enzyme (57 units for COX-1) in $0.1 \mathrm{~mol} / \mathrm{L} \mathrm{Tris} / \mathrm{HCl}(\mathrm{pH} \mathrm{8.1)}$. The oxidation of the substrate, the starter of the reaction, was measured at $25^{\circ} \mathrm{C}$ by monitoring the increase of absorbance at $630 \mathrm{~nm}$. The inhibition of the studied compound $4^{[23]}$ was determined after pre-incubation for $5 \mathrm{~min}$ with the enzyme in the presence of heme, and the reaction was started by adding AA and TMPD. This mixture was incubated for another $5 \mathrm{~min}$ and the absorbance was measured on a strip reader. For synthesized compound $4,10 \mu \mathrm{L}$ of scalar dilutions of the inhibitors in DMSO was added. Celecoxib, a potent and selective COX-2 inhibitor, was used as a reference drug. The average absorbance of all of the samples was determined. The absorbance of the test wells was normalized with background and calculated as the percentage of total activity: \% test inhibition=100 (1-test abs/total activity abs) where test abs=absorbance in the test well and total activity abs= absorbance in the well without any inhibitor. The percentage of inhibition was used to calculate the inhibition concentration $\mathrm{IC}_{50}$ of the compound (concen-tration at which there was $50 \%$ inhibition). 
In vivo methods The method of carrageenan-induced paw edema in rats ${ }^{[28]}$ was used to evaluate the anti-inflammatory activity. The treatment was performed $30 \mathrm{~min}$ before the injection of $50 \mu \mathrm{L}$ carrageenan $1 \%$ into the rat paw plantar surface. The foot volume was measured using a plethysmometer ${ }^{[29]}$ at $1 \mathrm{~h}$ intervals after the carrageenan injection for $3 \mathrm{~h}$, but the activity was acknowledged only for the third hour, in which maximum edema occurred. The inflammation index was calculated as the difference between the final volume of the carrageenan injected paw $\left(V_{\mathrm{t}}\right)$ and the initial volume of the same paw before injection $\left(V_{\mathrm{o}}\right)$, that is, inflammation index $\left(I_{\mathrm{i}}\right)=V_{\mathrm{t}}-V_{\mathrm{o}}$. The edema inhibition (\%) was calculated as the percentage of the difference of $I_{\mathrm{i}}$ according to the following formula: $\%$ inhibition $=\left(\left[\right.\right.$ pre-drug $\left.I_{\mathrm{i}}\right]$-[post-drug $\left.I_{\mathrm{i}}\right] /\left[\right.$ pre-drug $\left.\left.I_{\mathrm{i}}\right]\right) \times 100$.

In order to evaluate the anti-inflammatory effect of compound $4 \mathrm{a}-4 \mathrm{f}, 3$ doses were used. The $50 \%$ inhibition of the compound (by definition, the dose required to reduce the carrageenan-induced paw edema to $50 \%$ of the control group) was calculated. The compound was injected intraperitoneally (ip) using the following doses: 5.1, 7.6, and 11.4 $\mathrm{mg} / \mathrm{kg}$ for celecoxib (reference drug); 4.7, 7.2, and $10.7 \mathrm{mg} / \mathrm{kg}$ for compound $4 \mathrm{a} ; 4.5,6.4$, and $10.3 \mathrm{mg} / \mathrm{kg}$ for compound $4 \mathrm{~b}$; $5.0,7.5$, and $11.3 \mathrm{mg} / \mathrm{kg}$ for compound $4 \mathrm{c} ; 4.8,7.2$, and 10.9 $\mathrm{mg} / \mathrm{kg}$ for compound $4 \mathrm{~d} ; 5.2,7.8$, and $11.8 \mathrm{mg} / \mathrm{kg}$ for compound $4 \mathrm{e}$; and $5.1,7.6$, and $11.4 \mathrm{mg} / \mathrm{kg}$ for compound $4 \mathrm{f}$. The rats of the control group received the same volume of DMSO according to their weight.

Statistical analysis The data were expressed as mean \pm SEM. One-way ANOVA with Tukey's post-hoc test was used, and $P<0.05$ was considered statistically significant. The $\mathrm{IC}_{50}$ was calculated using the non-linear regression with cubic spline method.

\section{Results}

Molecular modeling and chemistry The docking study showed that compound 4 bound to the primary binding site of COX-2 with the sulfonamide $\mathrm{SO}_{2} \mathrm{NH}_{2}$ moiety interacting with the secondary pocket amino acid residues $\mathrm{Phe}^{518}$, $\mathrm{His}^{90}$, and $\mathrm{Val}^{523}$, which is comparable to $\mathrm{S}-58701$ (B) (Figure 2). One of the $\mathrm{O}$-atoms of the $\mathrm{SO}_{2} \mathrm{NH}_{2}$ substituent forms a hydrogen bond with the amide hydrogen of $\mathrm{Phe}^{518}(2.5 \AA)$. The $\mathrm{N}$-atom of the $\mathrm{SO}_{2} \mathrm{NH}_{2}$ forms a hydrogen bond with $\mathrm{His}^{90}(2.5 \AA)$. The substituted phenyl ring lies in a hydrophobic cavity lined by $\mathrm{Val}^{349}$. The ethyl sulfide (EtS) substituent is oriented in the direction of the polar amino acid $\mathrm{Arg}^{120}$, and $\mathrm{Tyr}^{355}$ and forms a weak hydrogen bond with them ( $4 \AA$ ). It is located in a hydrophobic region formed by $\mathrm{Val}^{116}$ and $\mathrm{Leu}^{531}$. Also, the amino $(\mathrm{NH})$ of imidazole forms another hydrogen bond with $\operatorname{Tyr}^{355}$ (3 $\AA$ ) (Figure 2). Considering the molecular modeling information, the synthetic reaction used for the synthesis of 4-[2-alkylthio5(4)-(4-substitutedphenyl)imidazole-4(5)-yl]benzenesulfonamides $(4 a-4 j)$ are outlined in Figure $3^{[23]}$.

In vitro assay The ability of compound $4 \mathrm{a}-4 \mathrm{j}$ to inhibit ovine COX-1 and COX-2 ( $\mathrm{IC}_{50}$ values, $\left.\mathrm{nmol} / \mathrm{L}\right)$ was determined using a colorimetric COX (ovine) inhibitor screening assay. In this regard, compound $4 \mathrm{a}-4 \mathrm{j}$ exhibited a broad range of COX-2 inhibitory potency (Table 1).

In vivo evaluation The potent and selective COX-2 inhibitors emerging from the in vitro studies were evaluated in the acute carrageenan-induced rat paw edema. Pretreatment with celecoxib $(0.02 \mathrm{mmol} / \mathrm{kg})$ intraperitoneally resulted in a marked decrease in paw inflammation when compared to control group $(P<0.001)$. Repeated experiments with the same dose of compound $4 \mathrm{a}-4 \mathrm{e}$ also showed significant differences $(P<0.001)$ in anti-inflammatory effects on carrageenan hind paw edema (Figure 4). Compound $4 \mathrm{a}-4 \mathrm{f}(0.02 \mathrm{mmol} / \mathrm{kg})$ induced protection against carrageenan-induced paw edema (Figure 5). The 50\% inhibition (by definition, the dose required to reduce the carrageenan-induced paw edema to $50 \%$ of that of the control) for compound $4 \mathrm{a}-4 \mathrm{f}$ ranged from $1.58-4.3 \mathrm{mg} / \mathrm{kg}$, while the $50 \%$ inhibition for the reference drug celecoxib was $2.90 \mathrm{mg} / \mathrm{kg}$ (Table 2).

\section{Discussion}

In this diarylheterocyclic class of COX-2 inhibitors, the initial modification was the insertion of sulfonamide at the para position of one of the phenyl ring and was held constant throughout of the structure-activity relationship (SAR) studies. Within the sulfonamide analogues (compound 4), modification at the alkylthio group at the $\mathrm{C}-2$ position of the imidazole ring gave variable results. In the presence of smaller C-4 substituents ( $\mathrm{H}, \mathrm{F} ; 4 \mathrm{a}-4 \mathrm{~d})$, increasing the size of alkylthio did not significantly affect the COX-2 inhibitory potency. However, in the presence of $\mathrm{C}-4$ phenyl chloro substituent (4e, 4f), the size of C-2 alkylthio had an effect on COX-2 inhibition and increasing the size led to an increase in COX-2 potency.

There was, however, some sensitivity to the electronic property at the 4-position of this aromatic ring, particularly with regards to COX-2 potency. In the EtS-substituted compound, $4 \mathrm{a}, 4 \mathrm{c}$, and $4 \mathrm{e}$, the analogs with an electron-withdrawing group $(4 \mathrm{c}, 4 \mathrm{e})$, tended to increase COX-2 potency. In contrast, electron-donating group had poor COX-2 activity. Therefore, methyl $(4 \mathrm{~g}, 4 \mathrm{~h})$ and methoxy $(4 \mathrm{i}, 4 \mathrm{j})$ substituents all worked poorly in this regard. These results suggested that the electronic property of the substituents at 


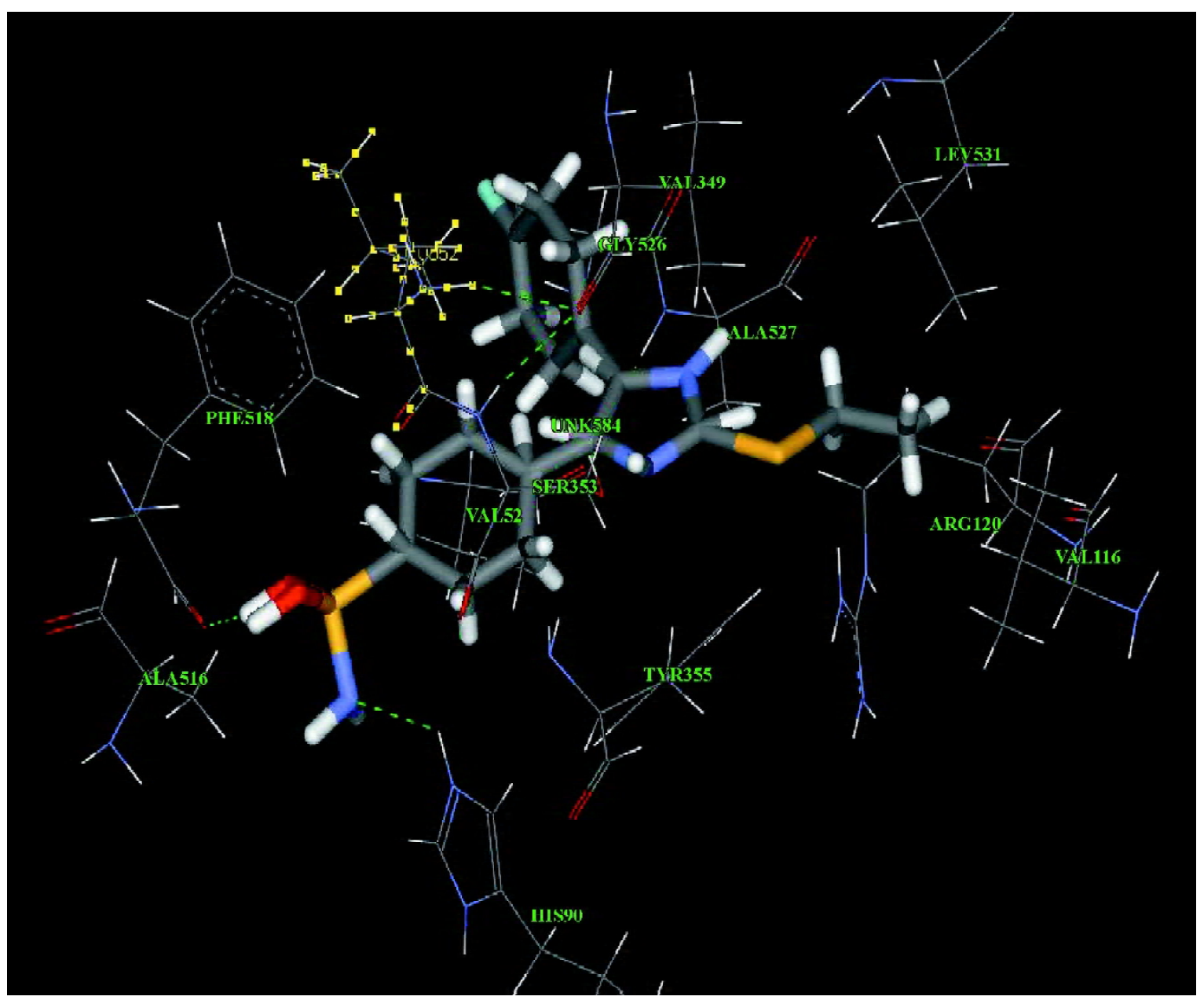

Figure 2. Docking of compound $4 \mathrm{c}$ (ball and stick) in the active site of murine COX-2.

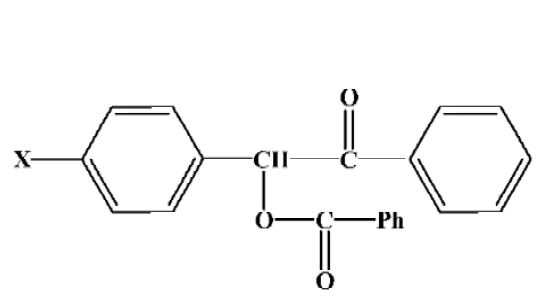

$1, \mathrm{X}=\mathrm{H}, \mathrm{F}, \mathrm{Cl}, \mathrm{Me}, \mathrm{OMe}$

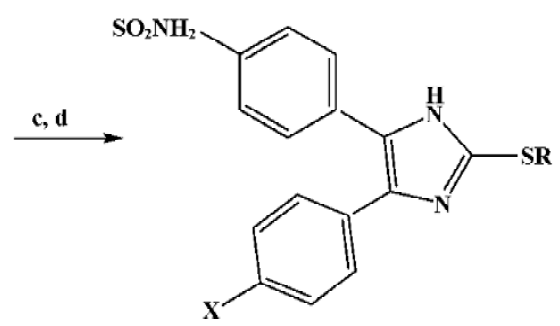<smiles>[X]c1ccc(-c2nc(S)[nH]c2-c2ccccc2)cc1</smiles>

2, $\mathrm{X}=\mathrm{H}, \mathrm{F}, \mathrm{Cl}, \mathrm{Me}, \mathrm{OMe}$

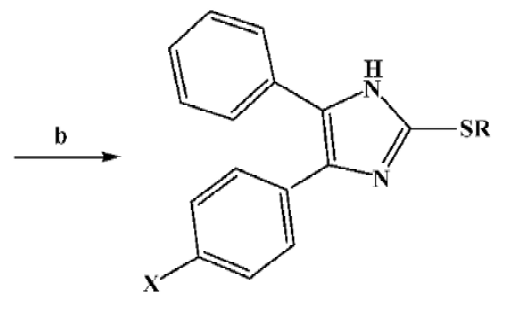

3, R=Me, Et $\quad \mathrm{X}=\mathrm{H}, \mathrm{F}, \mathrm{Cl}, \mathrm{Me}, \mathrm{OMe}$
4a, $X=H, R=M e$
4b, X=H, R=Et
4c, $X=F, R=M e$
$4 \mathrm{e}, \mathrm{X}=\mathrm{Cl}, \mathrm{R}=\mathrm{Me}$
4d, $X=F, R=E t$
4g, $X=M e, R=M e$
$4 \mathrm{i}, \mathrm{X}=\mathrm{OMe}, \mathrm{R}=\mathrm{Me} \quad 4 \mathrm{j}, \mathrm{X}=\mathrm{OMe}, \mathrm{R}=\mathrm{Et}$

Figure 3. Reagents and conditions: (a) amyl alcohol, ammonium thiocyanate, reflux, 5 h; (b) methanol, triethylamine, methyl or ethyl iodide, $25^{\circ} \mathrm{C}, 24 \mathrm{~h}$; (c) $\mathrm{ClSO}_{3} \mathrm{H}, 0{ }^{\circ} \mathrm{C}, 5 \mathrm{~h}$; (d) methanol, $\mathrm{NH}_{3}(\mathrm{aq}), 25^{\circ} \mathrm{C}, 24 \mathrm{~h}$. 
Table 1. In vitro inhibition of COX-1 and COX-2 by 4-[2-alkylthio-5(4)-(4-substitutedphenyl) imidazole-4(5)yl]benzenesulfonamides (4a$4 \mathrm{j})$. ${ }^{a}$ Values are the means of 3 determinations acquired using the colorimetric screening assay. Each value represents the Mean \pm SEM. ${ }^{b} S I$, selectivity index.<smiles></smiles>

\begin{tabular}{|c|c|c|c|c|c|}
\hline Compound & $\mathrm{X}$ & $\mathrm{R}$ & $\begin{array}{l}\text { COX-1 inhibition } \\
\mathrm{IC}_{50}, \mathrm{nmol} / \mathrm{L}^{\mathrm{a}}\end{array}$ & $\begin{array}{l}\text { COX-2 inhibition } \\
\mathrm{IC}_{50}, \mathrm{nmol} / \mathrm{L}\end{array}$ & $\begin{array}{c}\mathrm{IC}_{50} \mathrm{COX}-1 / \mathrm{COX}-2 \\
\mathrm{SI}^{\mathrm{b}}\end{array}$ \\
\hline $4 a$ & $\mathrm{H}$ & $\mathrm{Et}$ & $2.00 \pm 0.02$ & $1.50 \pm 0.03$ & 1.3 \\
\hline $4 b$ & $\mathrm{H}$ & $\mathrm{Me}$ & $>20$ & $1.55 \pm 0.02$ & 13.3 \\
\hline $4 c$ & $\mathrm{~F}$ & Et & $4.47 \pm 0.01$ & $1.23 \pm 0.03$ & 3.6 \\
\hline $4 d$ & $\mathrm{~F}$ & $\mathrm{Me}$ & $2.95 \pm 0.02$ & $1.35 \pm 0.03$ & 2.18 \\
\hline $4 \mathrm{e}$ & $\mathrm{Cl}$ & Et & $2.98 \pm 0.02$ & $1.25 \pm 0.02$ & 2.38 \\
\hline $4 \mathrm{f}$ & $\mathrm{Cl}$ & $\mathrm{Me}$ & $2.00 \pm 0.02$ & $2.00 \pm 0.03$ & 1 \\
\hline $4 g$ & $\mathrm{Me}$ & Et & $>10$ & $>1.5$ & - \\
\hline $4 \mathrm{~h}$ & $\mathrm{Me}$ & $\mathrm{Me}$ & $>10$ & $>2.5$ & - \\
\hline $4 \mathrm{i}$ & $\mathrm{OMe}$ & Et & $>29$ & $>7.0$ & - \\
\hline $4 j$ & $\mathrm{OMe}$ & $\mathrm{Me}$ & $>25$ & $>8.0$ & - \\
\hline Celecoxib & & & $2.95 \pm 0.02$ & $1.50 \pm 0.02$ & 1.96 \\
\hline
\end{tabular}

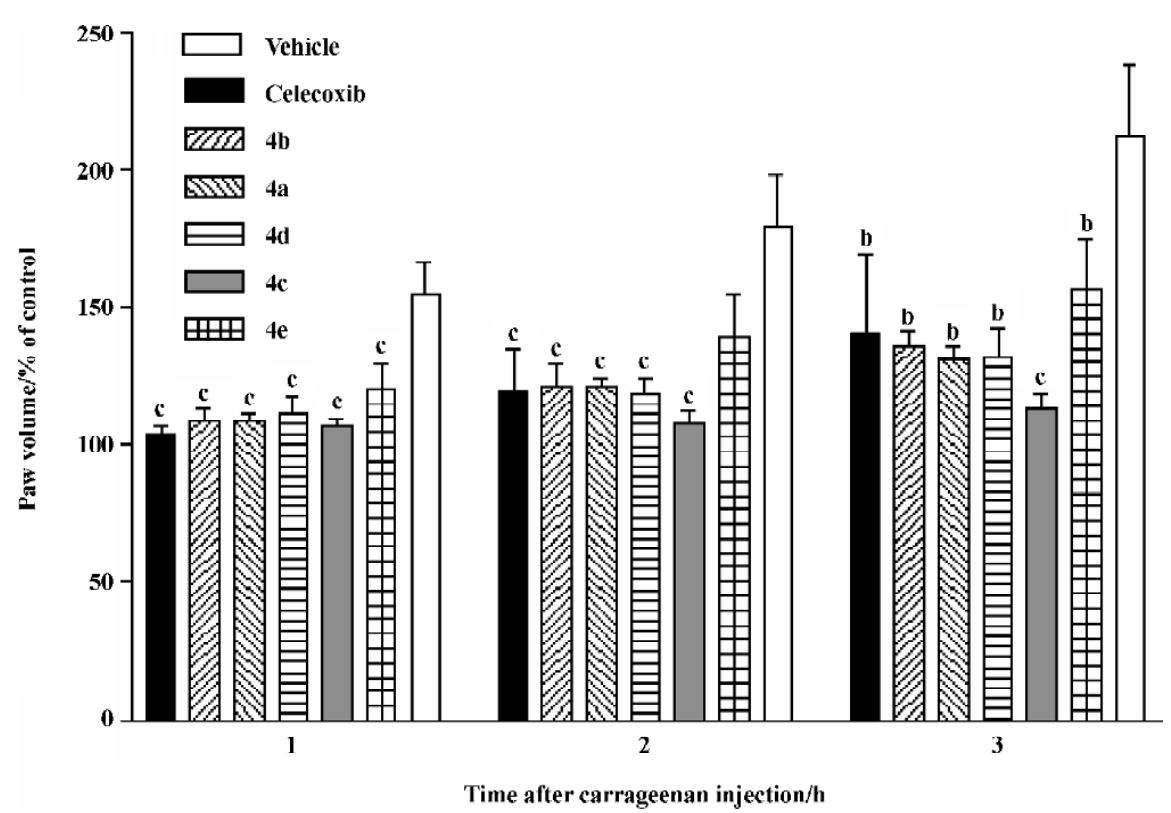

Figure 4. Time course of anti-inflammatory effect of different celecoxib derivatives $(0.02 \mathrm{mmol} / \mathrm{kg})$ on carrageenaninduced paw edema in rats. Carrageenan $1 \%(50 \mu \mathrm{g})$ was injected into the plantar surface of the right hind paw, $30 \mathrm{~min}$ after ip injection of the drugs. Increases in paw volume and edema were measured before and 1,2, and $3 \mathrm{~h}$ after the carrageenan injection. Values are presented as Mean $\pm \operatorname{SEM}(n=6) .{ }^{\mathrm{b}} P<0.05,{ }^{\mathrm{c}} P<0.01$ vs the vehicle group. the para position of the phenyl ring can influence the COX-2 inhibitory activity.

In the in vivo studies, the fluorine and hydrogen analogs $(4 a-4 d)$ showed a good inhibition on edema (Table 2$)$. The other derivative, compound $4 \mathrm{e}$ and $4 \mathrm{f}$, despite good COX-2 potency, was moderately active in vivo. In general, in vivo data prove our SAR of compound $4 \mathrm{a}-4 \mathrm{j}$. Its potency is greatly influenced by the substitution pattern and shows that para fluorine or hydrogen besides the $\mathrm{SO}_{2} \mathrm{NH}_{2}$ pharmacophore represents a series of anti-inflammatory agents, which pref- 
Table 2. In vivo evaluation of compound $4 \mathrm{a}-4 \mathrm{f}$. $n=6,95 \%$ confidence limits in parentheses, ${ }^{\mathrm{b}} P<0.05$.

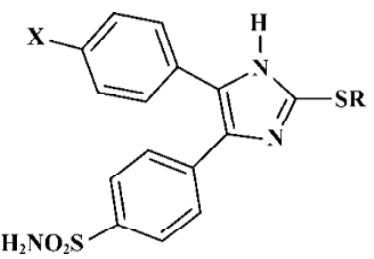

\begin{tabular}{|c|c|c|c|}
\hline Compound & $X$ & $\mathrm{R}$ & $\begin{array}{c}50 \% \text { inhibition }^{\mathrm{b}} \\
\mathrm{mg} / \mathrm{kg}\end{array}$ \\
\hline
\end{tabular}

\begin{tabular}{llll}
$4 \mathrm{a}$ & $\mathrm{H}$ & $\mathrm{Et}$ & $2.80( \pm 0.50)$ \\
$4 \mathrm{~b}$ & $\mathrm{H}$ & $\mathrm{Me}$ & $2.90( \pm 0.55)$ \\
$4 \mathrm{c}$ & $\mathrm{F}$ & $\mathrm{Et}$ & $1.58( \pm 0.80)$ \\
$4 \mathrm{~d}$ & $\mathrm{~F}$ & $\mathrm{Me}$ & $2.18( \pm 0.43)$ \\
$4 \mathrm{e}$ & $\mathrm{Cl}$ & $\mathrm{Et}$ & $4.30( \pm 1.88)$ \\
$4 \mathrm{f}$ & $\mathrm{Cl}$ & $\mathrm{Me}$ & $3.85( \pm 1.19)$ \\
Celecoxib & & & $2.90( \pm 0.53)$ \\
\hline
\end{tabular}

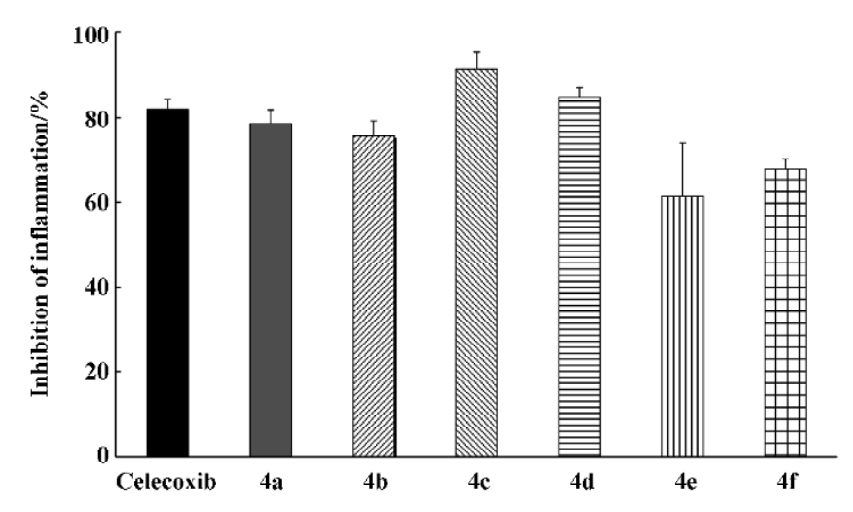

Figure 5. Anti-inflammatory effect of different doses of celecoxib derivatives $(0.02 \mathrm{mmol} / \mathrm{kg})$ on reducing carrageenan-induced paw edema. The drugs were administered $0.5 \mathrm{~h}$ before carrageenan injection. Edema was measured $3 \mathrm{~h}$ after the carrageenan injection. Each point is presented as mean $\pm \operatorname{SEM}(n=6)$.

erentially inhibit COX-2 with moderate potency and selectivity.

The potent in vitro and in vivo COX-2 inhibition exhibited by compound $4 \mathrm{c}$ is consistent with observations from a molecular modeling experiment where compound 4c was docked in the active site of the COX-2 enzyme. Molecular modeling studies show that the critical difference between the binding sites for COX-1 and COX-2 is at position 523 where COX-2 has the amino acid residue Val in place of the bulkier Ile in COX-1. This difference produces a secondary pocket extending off the primary binding site in $\mathrm{COX}-2$ that is absent in COX-1. Consequently, the combined volume of the primary binding site and the secondary pocket in COX-2 is about $25 \%$ larger than the volume of the COX-1 binding site ${ }^{[30,31]}$. This difference in volume can be exploited to manipulate COX-2 selectivity of the diarylheterocyclic class of COX-2 inhibitors by varying the volume of the drug and the appropriate placement of substituents with varying electronic and steric properties ${ }^{[32]}$. Designed compound $4 \mathrm{c}$ binds in the center of the active site with the phenylsulfonamide moiety oriented toward the secondary pocket region where it can undergo $H$-bonding via one of its $\mathrm{SO}_{2}$ oxygen atoms and $\mathrm{NH}_{2}$ group of the sulfonamide moiety with $\mathrm{Phe}^{518}$ and $\mathrm{His}^{90}$. Interestingly, the C-2 EtS substituent is located in a hydrophobic region, with the $S$-atom forming a weak hydrogen bond with the $\mathrm{Tyr}^{355}$ and $\mathrm{Arg}^{120}$. This shows the importance of the C-2 substituent in orienting the molecule such that the sulfonamide moiety inserts into the secondary pocket of COX-2. The ring $N$-atom of the central imidazole is oriented in the direction of the polar amino acid $\mathrm{Tyr}^{355}$, where this $N$-atom is about $3 \AA$ away from the $\mathrm{NH}_{2}$ of $\mathrm{Tyr}^{355}$. This interaction may disrupt the salt bridge between $\mathrm{His}^{90}, \mathrm{Arg}^{120}$, and $\mathrm{Tyr}^{355}$ at the mouth of the COX-2 active site (Figure 2). The similarity between the $K_{\mathrm{i}}(\mathrm{S}-8701 \mathrm{~B})$ as the reference drug and the $K_{\mathrm{i}}$ which was calculated for compound $4 \mathrm{c}$, shows that changing the structure from S-8701 B to compound 4c does not decrease the binding for the COX-2 enzyme. However, introducing the imidazole ring, ethyl sulfide SEt substituent, and $\mathrm{SO}_{2} \mathrm{NH}_{2}$ pharmacophore improves the binding, which is a result of the hydrogen bonds. These observations confirm the suggested SAR for COX-2 inhibitory activity.

Our observations provide a good explanation for these results: (i) compound 4 with good COX-2 inhibitory potency and selectivity can be designed by the appropriate placement of the para $P-\mathrm{SO}_{2} \mathrm{NH}_{2}$ pharmacophore on the C4 phenyl ring, in which the 2-alkylthio imidazole ring serves as a suitable central ring template; and (ii) COX-2 inhibitory potency and selectivity is sensitive to substituent electronic property at the para position of the phenyl ring where compound $4 \mathrm{~b}$ exhibits the best combination of potency and selectivity and compound $4 \mathrm{c}$ exhibits better potency on COX-2, but lower selectivity compared to compound $4 \mathrm{~b}$.

\section{References}

1 Hansch C, Sammes PG, Taylor JB. The rational design, mechanistic study and therapeutic application of chemical compounds. Comprehensive medicinal chemistry; v 6. Oxford: Pergamon Press; 1990 
2 Leblanc Y, Black WC, Chan CC, Charleson S, Delorme D, Denis $\mathrm{D}$, et al. Synthesis and biological evaluation of both enantiomers of L-761,000 as inhibitors of cyclooxygenase. Bioorg Med Chem Lett 1996; 6: 731-6.

3 Kalgutkar AS. Selective cyclooxygenase-2 inhibitors as nonulcerogenic anti-inflammatory agents. Exp Opin Ther Pat 1999; 9: $831-49$.

4 Reitz DB, Isakson PC. Cyclooxygenase-2 inhibitors. Curr Pharm Des 1995; 1: 211-20.

5 Penning T, Talley J, Bertenshaw S, Carter J, Collins P, Docter S, et al. Synthesis and biological evaluation of 1,5-diarylpyrazole class of cyclooxygenase-2 inhibitors: Identification of 4-[5-(4methylphenyl)-3-(trifluoromethyl)-1H-pyrazole-1-yl] benzenesulfonamide (SC-58635, Celecoxib). J Med Chem 1997; 40: 1347-65.

6 Prasit P, Wang Z, Brideau C, Chan CC, Charleson S, Cromlish W, et al. The discovery of rofecoxib, [MK 966, Vioxx (R), 4-(4'methylsulfonylphenyl)-3-phenyl-2(5H)-furanone], an orally active cyclooxygenase-2 inhibitor. Bioorg Med Chem Lett 1999; 9: $1773-8$.

7 Talley JJ, Brown DL, Carter JS, Graneto MJ, Koboldt CM, Masferrer JL, et al. 4-[5-methyl-3-phenylisoxazol-4-yl]-benzenesulfonamide, valdecoxib: a potent and selective inhibitor of COX-2. J Med Chem 2000; 43: 775-7.

8 Riendeau D, Percival MD, Brideau C, Charleson S, Dube D, Ethier $\mathrm{D}$, et al. Preclinical profile and comparison with other agents that selectively inhibit cyclooxygenase-2. J Pharmacol Exp Ther 2001; 296: 558-66.

9 Arico S, Pattingre S, Baury C, Gane P, Barbat A, Codogno P, et al. Celecoxib induces apoptosis by inhibiting 3-phosphoinositide dependent protein-kinase-1 activity in the human colon cancer. J Biol Chem 2002; 277: 27 613-21.

10 Davies G, Martin LA, Sacks N, Dowsett M. Cyclooxygenase-2 (COX-2), aromatase and breast cancer: a possible role for COX2 inhibitors in breast cancer chemoprevention. Ann Oncol 2002; 13: 669-78.

12 Liu HX, Kirschenbaum A, Yao S, Lee R, Holland FJ, Levine CAJ. Inhibition of cyclooxygenase-2 suppresses angiogenesis and the growth of prostate cancer in vivo. J Urol 2000; 164: 820-5.

13 Sawaoka H, Kawano S, Tsuji S, Tsuji M, Gunawan ES, Takei Y, et al. Cyclooxygenase-2 inhibitors suppress the growth of gastric cancer xenografts via induction of apoptosis in nude mice. Am J Physiol 1998; 274: G1061-7.

14 Khanna IK, Weier RM, Yu Y, Xu XD, Koszyk FJ, Collins PW, et al. 1,2-Diarylimidazoles as potent, cycloxygenase-2 selective, and orally active anti-inflammatory agents. J Med Chem 1997; 40: $1634-47$.

15 Wright JM. The double-edged sword of COX-2 selective NSAIDs. CMAJ 2002; 167: 1131-7.

16 Kontogiorgis CA, Hadjipavlou-Litina DJ. Synthesis and antiinflammatory activity of coumarin derivatives. J Med Chem 2005; 48: 6400-8.

17 Niedballa U, Bottcher I. Antiinflammatory 4,5-diphenyl-2-substituted-thio-imidazoles and their corresponding sulfoxides and sulfones. US patent 4440 776. 1984 Apr 03.
18 Navidpour L, Shafaroodi H, Abdi KH, Amini M, Ghahremani $\mathrm{MH}$, Dehpour AR, et al. Design, synthesis, and biological evaluation of substituted 3-alkylthio-4,5-diaryl-4H-1,2,4-triazoles as selective COX-2 inhibitors. Biorg Med Chem 2006; 14: $2507-$ 17.

19 Navidpour L, Amini M, Shafaroodi H, Abdi KH, Ghahremani MH, Dehpour AR, et al. Design and synthesis of new watersoluble tetrazolide derivatives of celecoxib and rofecoxib as selective cyclooxygenase-2 (COX-2) inhibitors. Biorg Med Chem Lett 2006; 16: 4483-7.

20 Navidpour L, Karimi L, Amini M, Vosooghi M, Shafiee A. Syntheses of 5-alkylthio-1,3-diaryl-1,2,4-triazoles. J Heterocyclic Chem 2004; 41: 201-4.

21 Karimi L, Navidpour L, Amini M, Shafiee A. Synthesis of 4,5Diaryl-1,2,3-thiadiazoles. Phosphorus Sulfur and Silicon and the Related Elements 2005; 180: 1593-600.

22 Johari Daha F, Matloubi H, Tabatabai SA, Shafiee B, Shafiee A. Synthesis of 1-(4-methylsulfonylphenyl)-5-aryl-1,2,3-triazoles and 1-(4-aminosulfonylphenyl)-5-aryl-1,2,3-triazoles. J Heterocyclic Chem 2005; 42: 33-7.

23 Salimi M, Amini M, Shafiee A. Syntheses of 2-alkylthio-(4,5diaryl) imidazoles. Phosphorus Sulfur Silicon 2005; 180: 158792.

24 Goodsell DS, Olson AJ. Automated docking of substrates to proteins by simulate annealing. Proteins: structure function and genetics 1990; 8: 195-202.

25 Morris GM, Goodsell DS, Huey R, Olson AJ. Distributed automated docking of flexible ligands to proteins: Parallel applications of autodock 2.4. J Computre-aided Mol Design 1996; 10 : 293-304.

26 Morris GM, Goodsell DS, Halliday RS, Huey R, Hart WE, Belew $\mathrm{RK}$, et al. Automated docking using Lamarckian genetic algorithm and an empirical binding free energy function. J Comp Chem 1998; 19: 1639-62.

27 Kulmacz RJ, Lands WEM. Requirements for hydroperoxide by the cyclooxygenase and peroxidase activities of prostaglandin $\mathrm{H}$ synthase. Prostaglandins 1983; 25: 531-40.

28 Winter CA, Rislet EA, Nuss GW. Carrageenan-induced edema in hind paw of the rat as an assay for anti-inflammatory drugs. Proc Soc Exp Biol Med 1962; 111: 544-7.

29 Ahmadiani A, Fereidoni M, Semnanian S, Kamalinejad M, Saremi S. Antinociceptive and anti-inflammatory effects of sambucus ebulus rhysome extracts in rats. J Ethnopharmacol 1998; 61: 229-35.

30 Luong F, Miller A, Barnett J, Chow J, Ramesha C, Browner MF. Flexibility of the NSAIDs binding site in the structure of human cyclooxygenase-2. Nat Struct Biol 1996; 3: 927-33.

31 Gierse JK, McDonald JJ, Hauser SD, Rangwala SH, Koboldt CM, Seibert K. A single amino acid difference between cyclooxygenase1 (COX-1) and 2-(COX-2) reverse the selectivity of COX-2 specific inhibitors. J Biol Chem 1996; 271: 15810-4.

32 Kurumbail RG, Stevens AM, Gierse JK, McDonald JJ, Stegman RA, Pak JY, et al. Structural basis for selective inhibition of cyclooxygenase-2 by anti-inflammatory agents. Nature 1996; 384: $644-8$. 